\title{
Physicomechanical Properties of Epoxyurethane Biocomposites Strengthened with Hemp Wood Core
}

\author{
Tetiana Samoilenko*, Larysa Yashchenko, Natalia Yarova, Oleh Babich, \\ Oleksandr Brovko \\ Institute of Macromolecular Chemistry of the National Academy of Science of Ukraine, \\ Kharkivske shose, 48, Kyiv 02160, Ukraine \\ s_tf@ukr.net
}

Keywords: polymer biocomposites, epoxyurethanes, epoxydized soybean oil, hemp filler, matrixfiller affinity.

Hemp wood core (HWC) filled Si-containing epoxyurethane biocomposites, in which diane epoxy resin was replaced with epoxidized soybean oil (ESO), were obtained. It was shown that the tensile strength of ESO-containing polymer was higher, and the flexural strength was lower than those of original polymer. HWC was especially effective strengthening filler for modified epoxyurethanes, because in that case mechanical properties of composites were higher than those of unfilled polymer matrices. Particularly, flexural and tensile strength of unfilled epoxyurethane with maximum content of ESO were 8.1 and 6.8 MPa respectively, while in corresponding composite they reached 17.3 and 15.7 MPa.

\section{Introduction}

Bio-based polymer materials are now of great scientific interest due to their lower environmental footprint than that of the petrolbased ones. But in order to get widespread application, natural materials have to exhibit as good operational properties and durability as synthetic ones do, that is however often a really challenging task for scientists [1,2]. Taking this into account, composites made of plant fillers and matrices based on natural/synthetic polymer blends are considered to be an acceptable ecological alternative to fully synthetic composites [3, 4].
In recent decades, different plants were widely used to obtain reinforcing fillers for polymer matrices [1, 3-7]. Among them, hemp is especially abundant in Europe. It is a fastgrowing plant consisting of fibres and wood core (also known as hurd or sheaves) [8]. While hemp fibre is intensively used in the synthesis of biocomposites, hemp wood core (HWC), which is a chopped part of the stem obtained during its primary processing, is not. It is a by-product of hemp industry, $70-80 \%$ of which is disposed via combustion or landfilling [8]. Still, HWC is very promising lignocellulosic filler for polymer 
composites due to its biodegradability, sustainability, low cost, and low density [9-12].

Biocomposites with plant fillers are known to be obtained for both thermoplastic [14 , 13] and thermoset polymers (mostly for polypropylene and epoxy polymers respectively) $[7,14,15]$. Simultaneously, organic-inorganic matrices are rarely applied for this purpose. In our previous works $[12,16,17]$ HWC was used as filler of Si-containing epoxyurethane polymer matrix, where inorganic component enhanced fire-retardant properties, UV- and thermal resistance [18]. Due to the presence of hydroxyl groups on the surface of $\mathrm{HWC}$, it is able to form covalent and hydrogen bonds with a polymer matrix, which favours the formation of a strong composite material [17]. But considering the environmental demands, the composition of polymer matrix was changed to make it "greener". Epoxidized soybean oil (ESO) with many attractive characteristics of common epoxy resins, which nowadays is a widespread component of polymer biocomposites $[15,19$ 23], was used to replace synthetic diane epoxide ED-20.

The matrix-filler interaction, changing with the modification of polymer, should be investigated and, if possible, enhanced, because the poor compatibility/adhesion between the hydrophilic fibres and the hydrophobic matrix materials is considered to be the main problem leading to reduced mechanical properties in natural fibre reinforced polymers [24].
Therefore, the aim of the given research is to investigate matrix-filler affinity as well as the physicomechanical properties of HWCstrengthened biocomposites, obtained on the basis of organic-inorganic epoxyurethane polymer matrix with partial or complete replacement of the synthetic epoxy component with sustainable ESO.

\section{Experimental part}

\section{Materials}

For the synthesis of epoxyurethane matrices the following reagents were used:

- polyisocyanate (PIC) commercialized under the name of "Lupranat M 20S" IsoPMDI 92140 - a mixture of isomers of diphenylmethane diisocyanate and oligomeric compounds (mass fraction of isocyanate groups - 30.0\%, density - $1.2446 \mathrm{~g} / \mathrm{cm}^{3}$ ) - was purchased from BASF Polyurethanes $\mathrm{GmbH}$, Germany;

$$
\text { - epoxy diane resin ED-20 }
$$

$(\mathrm{M}=390 \mathrm{~g} / \mathrm{mol}$, the content of epoxy groups $19.8 \%$, the content of hydroxyl groups $-1.9 \%$ ) was purchased from Sigma-Aldrich, USA;

- ESO (epoxy equivalent - $250 \mathrm{~g} / \mathrm{mol}$, epoxy group content $-6.1 \%$ ) was purchased from Sigma-Aldrich, USA;

- aqueous solution of sodium silicate (SS) (silicate module - 2.9-3.0, the percentage of free water - 56.0\%) was purchased from SigmaAldrich, USA.

HWC, which served as filler, was purchased from Institute of bast crops of the NAS 
of Ukraine. Particles with size ranging from 0.05 to $5.0 \mathrm{~mm}$ were used. The shape and size of the particles were evaluated by MBI-6 optical microscope in transmitted light at a magnification of $\mathrm{x} 2250$ (object lens with a numerical aperture of $\mathrm{A}=1.25$, resolution $\mathrm{R} \approx 300 \mathrm{~nm}$ ). The particles of the desired size were selected by fractionation through a sieve (model 029).

\section{Synthesis}

Epoxyurethane EU-0 (Table 1) was chosen as a neat polymer matrix for his good mechanical properties [12]. To synthesize a set of other matrices, its composition was modified by the introduction of different amount of ESO instead of ED-20. Isocyanate component, epoxy component, and sodium silicate were combined in a mass ratio of $80 / 20 / 20$. The composition of the synthesized polymer matrices are shown in table 1.

Table 1. The composition of the synthesized epoxyurethane polymer matrices

\begin{tabular}{|l|l|l|l|}
\hline Name & $\begin{array}{r}\text { Isocyanate } \\
\text { component, } \\
\text { w.p. }\end{array}$ & $\begin{array}{c}\text { Epoxy } \\
\text { component, } \\
\text { w.p. }\end{array}$ & w.p. \\
\hline EU-0 & 80 (PIC) & $\begin{array}{l}20 \text { (ED-20/ESO } \\
=100 / 0)\end{array}$ & 20 \\
\hline EU-30 & 80 (PIC) & $\begin{array}{l}20(\text { ED-20/ESO } \\
=70 / 30)\end{array}$ & 20 \\
\hline EU-50 & 80 (PIC) & $\begin{array}{l}20(\text { ED-20/ESO } \\
=50 / 50)\end{array}$ & 20 \\
\hline EU-70 & 80 (PIC) & $\begin{array}{l}20(\text { ED-20/ESO } \\
=30 / 70)\end{array}$ & 20 \\
\hline EU-100 & 80 (PIC) & $\begin{array}{l}20(\text { ED-20/ESO } \\
=0 / 100)\end{array}$ & 20 \\
\hline
\end{tabular}

The epoxy component was prepared by mixing epoxy resin and epoxidized soybean oil (ED-20/ESO) in the ratios of 100/0, 70/30, 50/50, $30 / 70$, and $0 / 100$ at $60^{\circ} \mathrm{C}$ and vigorous stirring for 60 min until formation of a homogeneous mixture.

The epoxy component was introduced into the isocyanate one and stirred at $900 \mathrm{rpm}$ for $3 \mathrm{~min}$. Then SS was added under stirring at 900$1000 \mathrm{rpm}$ for $3 \mathrm{~min}$.

Filled biocomposites with a HWC content of $60-70 \mathrm{wt} \%$ were made in a closed form with a size of $150 \times 20 \mathrm{~mm}$ at $140^{\circ} \mathrm{C}$ under a $10 \mathrm{MPa}$ pressure.

\section{Methods}

To determine the surface tension of the investigated adhesives, the sessile drop method was used to measure the contact angles of epoxyurethane matrices on Teflon plates (with known surface tension $\Theta$ ) with a horizontal microscope MG. Using a digital ocular camera, microphotographs of the droplets reached equilibrium were obtained. The photographs were adapted by the image processing software package ImageJ [25]. The values of the contact angles were computed using the DropSnake algorithm implemented in the Drop Shape Analysis plugin. Surface tension values were calculated from the equation 1 [25].

$$
\sigma_{1}=2 \sigma_{\mathrm{s}} /(1+\cos \theta)
$$

The density of biocomposites was measured by hydrostatic weighing [26]. For this purpose, Radwag WPS 60/18C:C/2 scales with a 
built-in automatic density detection function and isooctane as a liquid with a known density were used.

Mechanical properties of polymer biocomposites were determined for moulded samples with a size of $150 \times 20 \times 5 \mathrm{~mm}$ according to State standard 11262-80 and Ukrainian State standard 10635-2009 for tensile and flexural strength respectively. The tests were conducted for five different specimens, and the average values are represented.

\section{Theory}

Analysis of interfacial phenomena in the system substrate/adhesive, where polymer matrix is an adhesive and filler is a substrate, allows considering the colloid-chemical factors and the selectivity of surface interactions of components in predetermination of the adhesive properties of polymer formulations [27, 28].

Polymer matrices used in the surface tack development of fillers should provide complete wetting of the substrate surface, as well as interfacial or adsorption interaction at the polymer-filler interface [27]. Adhesion is determined by the interaction of components at the interface. This interaction depends on the values that stipulate the properties of the contacting surfaces, first of all, on surface tension and surface energy.

To estimate the adhesive interaction, it is necessary to use values that can be determined experimentally, such as contact angle $\Theta$ and the surface tension of the liquid $\sigma_{\mathrm{lg}}$. The product of the surface tension of the liquid and the cosine of the contact angle is the adhesion tension, or the wetting energy [28].

$$
\mathrm{W}_{\mathrm{e}}=\sigma_{\mathrm{lg}} \cdot \cos \theta
$$

Usually, the liquid-solid interaction is estimated by the work of adhesion, which must be spent to separate liquid from a solid surface, that is, to restore the initial state of the contacting bodies. When liquid comes into contact with a solid surface, the free surface energy is equal to $\gamma_{\mathrm{sl}}$, and after the separation of bodies it becomes equal to $\left(\gamma_{\mathrm{lg}}+\gamma_{\mathrm{sg}}\right)$. The difference between these values is the work of adhesion (Dupre equation) [28]:

$$
\mathrm{W}_{\mathrm{A}}=\gamma_{\mathrm{lg}}+\gamma_{\mathrm{sg}}-\gamma_{\mathrm{sl}}
$$

From a combination of this equation (3) and the Young's one the following formula is obtained:

$$
\mathrm{W}_{\mathrm{A}}=\gamma_{1}(1+\cos \Theta)
$$

From equations $(3,4)$ it is seen that to achieve good adhesion, the values of both the surface energy and the surface tension of liquid (matrix) should be high. At the same time for a complete and uniform wetting of filler by matrix, the values of surface energy and surface tension of substrate (filler) should exceed the corresponding values of adhesives, namely [29]:

$$
\begin{aligned}
& \gamma_{\text {substrate }}>\gamma_{\text {adhesive }}, \\
& \sigma_{\text {substrate }}>\sigma_{\text {adhesives }}
\end{aligned}
$$

High adhesion strength of polymer matrix with filler is a mandatory condition to create composite materials with good physical and mechanical properties. This requires the mutual action of filler and matrix leading to a strong 
connection between their surfaces. Therefore, the investigation of the nature of the matrix-filler interface interaction is very important not only from a theoretical but also from a practical point of view.

In order to evaluate the possibility of epoxyurethane matrix to compatibilize with HWC effectively according to the condition (6), it is necessary to determine the values of their surface tensions.

In the literature there is no available information on the value of the surface tension of HWC, but its determination is very important for predicting the adhesive strength and performance properties of composite materials based on it.

There are many methods for measuring the surface tension of solids, including HWC, but the only theoretically justified way to determine this value is still absent [29]. At the same time, the most accessible and technically feasible method consists in measuring the surface tension of a solid body based on the results of studying the equilibrium of three phases - solid, liquid, and gaseous ones - while wetting of a solid by liquids in air. This method can be implemented by measuring the contact angles.

Using the equation (7), the surface energy of HWC was calculated from the obtained values of contact angles and surface tension of liquids spread on filler samples, which is known to be almost equal to the surface tension for solids [29].

$$
\sigma_{\lg }=0,5 \sigma_{\mathrm{lg}}(1+\cos \theta)
$$

\section{Results and discussion}

Epoxyurethane matrices surface tension determination

The measured values of surface tension of the investigated adhesives are given in Table 2.

Table 2. The surface tension of the investigated adhesives

\begin{tabular}{|c|c|c|}
\hline $\begin{array}{c}\text { Type of } \\
\text { matrix }\end{array}$ & $\begin{array}{c}\text { Contact angle } \\
\Theta, \text { degrees }\end{array}$ & $\begin{array}{c}\sigma_{1}, \\
\mathrm{MJ} / \mathrm{m}^{2}\end{array}$ \\
\hline EU-0 & 69.54 & 41.50 \\
\hline EU-30 & 74.65 & 44.28 \\
\hline EU-50 & 70.63 & 42.15 \\
\hline EU-70 & 67.52 & 40.51 \\
\hline EU-100 & 67.72 & 40.61 \\
\hline
\end{tabular}

The obtained results show that the surface tension of epoxyurethane polymer matrices changes with introduction of ESO. In order to predict the adhesion characteristics of matrices in certain composite materials, it is also necessary to investigate the surface properties of filler.

$H W C$ surface tension determination

The values of the adhesives surface tension and the cosines of the contact angles of HWC surface wetting by adhesives were used in calculations, and the results are summarized in Table 3. 
Table 3. The surface tension of HWC

\begin{tabular}{|c|c|c|}
\hline Adhesive & $\begin{array}{c}\text { Contact } \\
\text { angle } \Theta, \\
\text { degrees }\end{array}$ & $\sigma_{\mathrm{s}}, \mathrm{MJ} / \mathrm{m}^{2}$ \\
\hline EU-0 & 21.11 & 40.11 \\
\hline EU-30 & 16.44 & 43.37 \\
\hline EU-50 & 9.32 & 41.87 \\
\hline EU-70 & 8.56 & 40.29 \\
\hline EU-100 & 12.58 & 40.16 \\
\hline
\end{tabular}

The surface tension of HWC calculated using the proposed formula (7) showed an average value equal to $41.16 \mathrm{MJ} / \mathrm{m}^{2}$. In order to achieve complete wetting and good adhesion, in compliance with condition(6), the surface tension of polymer matrices used in the formation of biocomposites should be lower than the surface tension of filler, namely lower than $41.16 \mathrm{MJ} / \mathrm{m}^{2}$. Analysis of the obtained results (Table 2) indicates that this requirement is best satisfied for synthesized epoxyurethanes for EU70 and EU-100 matrices with predominant partial and complete replacement of synthetic epoxide ED-20 by ESO. Therefore, the higher content of ESO in the composition of organicinorganic epoxyurethane polymer matrices should result in the better wetting of HWC surface.

Evaluation of the epoxyurethane matrices work of adhesion

The calculated values of the epoxyurethane polymers work of adhesion determined by formulas 2,3 are represented in Table 4.

Table 4. The epoxyurethane matrices work of adhesion

\begin{tabular}{|c|c|}
\hline Type of matrix & Work of adhesion, $\mathrm{MJ} / \mathrm{m}^{2}$ \\
\hline EU-0 & 77.58 \\
\hline EU-30 & 78.44 \\
\hline EU-50 & 79.27 \\
\hline EU-70 & 79.33 \\
\hline EU-100 & 78.96 \\
\hline
\end{tabular}

Although the obtained values have similar meanings, it may be noticed that the work of adhesion is the lowest for the basic matrix EU0 , while it is the highest for matrices EU-50 and EU-70.

Measurements of the density of biocomposites

The analysis of the density of composite materials may not only show how light or heavy they are, but also provide a basic idea of their structure. Experimental values of the density of biocomposites are given in table 5 .

The obtained data shows that the introduction of ESO with flexible aliphatic chains into the composition of matrices leads in all cases to the formation of biocomposites with lower values of density than in unmodified matrix EU-0. The lowest density was achieved at the complete replacement of ED-20 (with a density of $1.24 \mathrm{~g} / \mathrm{cm}^{3}$ ) by ESO (with a density of $\left.0.99 \mathrm{~g} / \mathrm{cm}^{3}\right)$. 
Table 5. Experimental density of biocomposites

\begin{tabular}{|c|c|c|}
\hline \multirow{2}{*}{$\begin{array}{c}\text { Type of } \\
\text { matrix }\end{array}$} & \multicolumn{2}{|c|}{ Experimental density, $\mathrm{g} / \mathrm{cm}^{3}$} \\
\cline { 2 - 3 } & $60 \%$ & $70 \%$ \\
\hline EU-0 & 0.703 & 0.726 \\
\hline EU-30 & 0.571 & 0.640 \\
\hline EU-50 & 0.587 & 0.656 \\
\hline EU-70 & 0.585 & 0.652 \\
\hline EU-100 & 0.564 & 0.638 \\
\hline
\end{tabular}

At the same time, as shown in the Table 5, the density is higher for the biocomposites with the larger content of HWC (70\%), which may indicate the formation of a dense composite structure due to the good interaction of the filler and the matrix.

\section{Mechanical properties of biocomposites}

At first, it was important to compare the mechanical properties of unfilled polymer epoxyurethane matrices and to analyze the change in these properties with the introduction of HWC filler. For this purpose, the effect of $60 \%$ filling of biocomposites on flexural strength (Figure 1a) and tensile strength (Figure 1b) was investigated in the extreme cases of unmodified EU-0 and completely modified EU-100.

Comparison of the strength of unfilled polymers shows that the ESO-containing matrix has lower flexural strength (Figure 1a) and higher tensile strength (Figure 1b) than unmodified EU-0. It is attributed to the replacement of rigid benzene fragments of ED20 in the matrix structure by flexible aliphatic fragments in ESO, and to the lower crosslinking density of the polymer $[10,17]$.
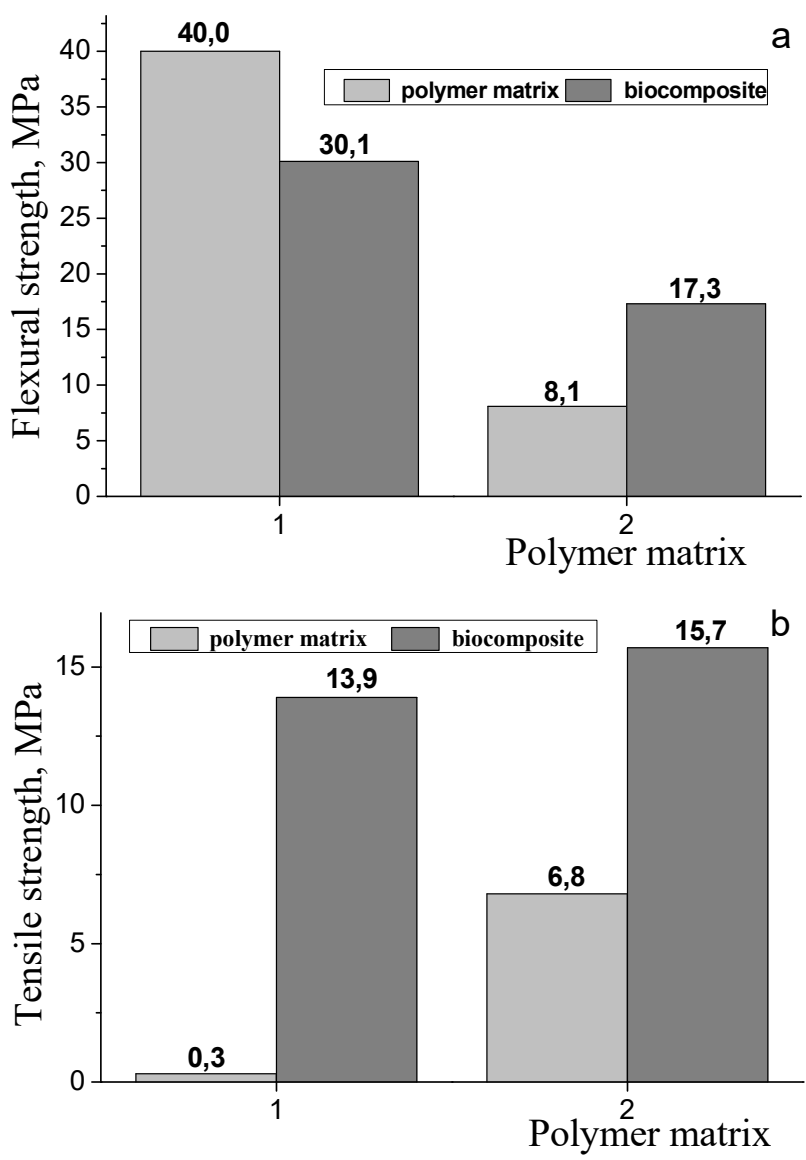

Figure 1. Flexural strength (a) and tensile strength (b) of matrices and biocomposites based on them: 1) EU-0; 2) EU-100

The introduction of HWC into the basic epoxyurethane matrix causes a huge increase in tensile strength (Figure 1b) but a decrease in the flexural strength (Figure 1a), possibly due to the rigid polymer matrix in this case.

At the same time, HWC improves both flexural and tensile strength of the ESO-modified matrix, each of them doubling after filling (Figure 1). It may be due to the fact that EU-100 wets the surface of filler better than EU-0 (Table 2) and provides greater access to the 
functional (isocyanate) groups of the matrix to react with the hydroxyl groups of the filler [17], thus enhancing the matrix-filler interaction and, consequently, the mechanical properties of biocomposite.

Then, the dependence of the flexural strength of biocomposites on the amount of ESO in the epoxyurethane matrix as well as on the amount of filler was investigated (Fig. 2).

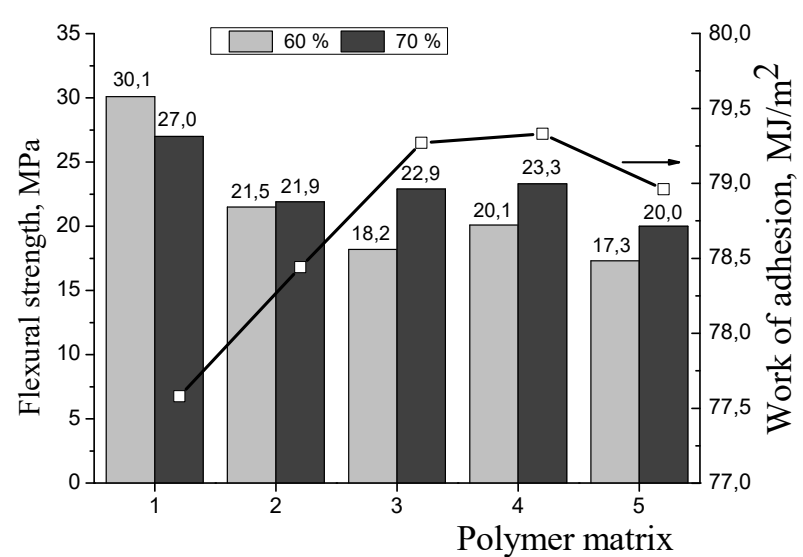

Figure 2. Flexural strength of biocomposites (with 60 and $70 \%$ load) depending on the amount of ESO in the epoxyurethane matrix: 1) EU-0; 2) EU-30; 3) EU-50; 4) EU-70; 5) EU-100

As expected, the flexural strength of the composite based on unmodified matrix is higher than that of composites with ESO-containing matrices (Figure 2). At the same time, there is no obvious dependence of the flexural strength of biocomposites on the amount of ESO introduced into the matrix. It may be caused by the simultaneous influence of at least two factors: changes in the polymer chemical composition and in physicochemical interactions in the polymer-filler system. Thus, on the one hand, the larger content of ESO results in the larger fraction of flexible aliphatic fragments and, consequently, in higher tensile and lower flexural strength. On the other hand, changing the epoxy component of the epoxyurethane also changes the adhesive interactions, in particular because of the different wetting of filler by matrices.

Although there is no dependence of the flexural strength on the value of surface tension, a relation can be evidenced with the calculated work of adhesion as a more complete characteristic of the system (Figure 2). The dependence is revealed for composites with $70 \%$ filler load, for which adhesive interactions may be more important. Thus, biocomposites EU-50 and EU-70 based on matrices with the highest values of the work of adhesion have the highest flexural strength among ESO-containing composites. This points out that given matrices are uniformly distributed on the surface of the HWC and wet it well.

Taking this into account, the lowering of flexural strength with increasing from 60 to $70 \%$ the filler content of the composite based on unmodified matrix EU-0 (as opposed to ESOcontaining composites) can be explained not only by the dominant contribution of the polymer (as in Figure 1a), but also by the lowest work of adhesion, which testifies to the worst polymerfiller interaction in the case of using unmodified EU-0 as a matrix. 


\section{Conclusions}

Investigation of the mechanical properties of biocomposites demonstrated that HWC is a particularly effective reinforcing filler for ESO-modified epoxyurethanes with low strength characteristics. Both flexural and tensile strength of composites based on EU-100 are twice higher than those of the corresponding unfilled matrix.

Clear dependence of the composites strength on the content of ESO can not be traced, since it is determined by at least two kinds of changes: the nature of the polymer and the matrix-filler interaction. There is still some correlations between the strength of composites with $70 \%$ HWC load and calculated work of adhesion. In particular, composites based on EU50 and EU-70 with the highest work of adhesion also show the highest strength in a set of modified composites.

Due to the good wetting of HWC surface by ESO-modified polymer matrices, it is possible to introduce a large proportion of plant filler (60$70 \%$ ) into the composition of biocomposites, and thus to obtain not only safe and environmentally friendly, but also cheap materials with reduced density.

\section{References}

[1] Begum K, Islam MA. Natural fiber as a substitute to synthetic fiber in polymer composites: a review. Res. J. Engineering Sci. 2013;2(4):46-53.

[2] Pickering KL, Efendy MGA, Le TM. A review of recent developments in natural fibre composites and their mechanical performance. Compos. Part A Appl. Sci. Manuf. 2016;83:98-112.
[3] Mochane MJ, Mokhena TC, Mokhothu TH, Mtibe A, Sadiku ER, Ray SS, Ibrahim ID, Daramola OO. Recent progress on natural fiber hybrid composites for advanced applications: A review. EXPRESS Polym. Lett. 2019;13(2):159-198.

[4] Khan T, Sultan Hameed MTB, Ariffin AH. The challenges of natural fiber in manufacturing, material selection, and technology application. A Review. J. Reinf. Plast. Compos. 2018;37:770-779.

[5] Wendi L, Tianshun X, Renhui Q. Improvement of properties for biobased composites from modified soybean oil and hemp fibers: dual role of diisocyanate. Composites Part A: App. Sc. Manufacturing. 2016;90:278-285.

[6] Athijayamani A, Stalin B, Sidhardhan S, Batcha AA. Mechanical properties of unidirectional aligned bagasse fibers/vinyl ester composite. J Polym Eng. 2016;36:157-164.

[7] Mittal V, Saini R, Sinha S. Natural fibermediated epoxy composites. A review. Composites Part B. 2016;99:425-435.

[8] Stevulova N, Estokova A, Cigasova J, Schwarzova I, Kacik F, Geffert A. Thermal degradation of natural and treated hemp hurds under air and nitrogen atmosphere. J Therm Anal Calorim. 2017;128:1649-1660.

[9] Bohdanova OF, Dombrovska OP, Babich SS, Dombrovskyi AH. Vyznachennia mozhlyvosti oderzhannia voloknystyskh napivfabrykativ $\mathrm{Z}$ nenarkotychnykh konopel. Visnyk KhNTU. 2018;64(1):67-74.

[10] Kuzmina TO, Shynkaruk MV, Shamshura MV. Analiz ta shliahy rozvytku produktsiyi iz konoplianoyi syrovyny. Visnyk KhNTU. 2017;60(1):120124.

[11] Manaia JP, Manaia AT, Rodriges L. Industrial Hemp Fibers: An Overview. 2019;7(12):106.

[12] Yashchenko LM, Yarova NV, Vorontsova LO, Brovko OO. Fizyko-mekhanichni vlastyvosti polimernykh kompozytiv, armovanykh 
konoplianoyu kostrytseyu. Voprosy Khimii i

Khimicheskoi Tekhnologii. 2020;5:104-111.

[13] Panthapulakkal S, Sain M. Studies on the water absorption properties of short hemp-glass fiber hybrid polypropylene composites. J Compos Mater. 2007;41(15):1871-1883.

[14] Ozkur S, Sezgin H, Akay E, YalcinEnis I. Hybrid bio-based composites from blends of epoxy and soybean oil resins reinforced with jute woven fabrics. Mater. Res. Express. 2020;7(1):015335.

[15] Mustapha R, Rahmat A, Abdul Majid R, Mustapha S. Vegetable oil-based epoxy resins and their composites with bio-based hardener: a short review. Polymer-Plastics Technology and Materials 2019;58(12):1311-1326

[16] Yashchenko LM, Yarova NV, Vorontsova LO, Babich OV, Brovko OO, Horbatenko OM. Fizyko-khimichni ta mekhanichni kharakterystyky epoksyuretanovykh kompozytiv. Ukrainskyi khimichnyi zhurnal. 2020; 86(8):134-143.

[17] Yashchenko LM, Yarova NV, Samoilenko TF, Brovko OO. Syntez epoksyuretanovoho spoluchnoho dlia biokompozytsiynykh materialiv. Voprosy Khimii i Khimicheskoi Tekhnologii. 2019;1:7379.

[18] Prydatko AB. Orhanosylikatni polimerni sumishi na osnovi ridkykh stekol ta izotsianativ. Dys. kand. khim. nauk: K.; 1998, pp.79-95.

[19] Zhang J, Hu S, Zhan G, Tang X, Yu Y. Biobased nanocomposites from clay modified blend of epoxidized soybean oil and cyanate ester resin. Prog. Org. Coat. 2013;76(11):1683-1690.

[20] Miyagawa H, Mohanty AK, Burgueno R, Drzal LT, Misra M. Novel biobased resins from blends of functionalized soybean oil and unsaturated polyester resin. J. Polym. Sci. Pol. Phys. 2007;45:698-704.

[21] Chang KH, Richard PW. Development of a bio-based composite material from soybean oil and keratin fiber. J. Appl. Polym. Sci. 2005;95:1524-1538.
[22] Tingting C, Yuchao W, Jianhui Q, Mingen F, Renhui Q, Wendi L. Interfacial compatibilization via in-situ polymerization of epoxidized soybean oil for bamboo fibers reinforced poly(lactic acid) biocomposites. Composites Part A: App. Sc. Manufacturing. 2020;138:170-180.

[23] Fernandes FC, Kirwan K, Wilson PR, Coles SR. Sustainable Alternative Composites Using Waste Vegetable Oil Based Resins. Journal of Polymers and the Environment. 2019;27:2464-2477.

[24] Dittenber DB, GangaRao HVS. Critical review of recent publications on use of natural composites in infrastructure. Composites Part A. 2012;43:1419-1429.

[25] Stalder AF, Kulik G, Sage D, Barbieri L, Hoffmann P. Snake-based approach to accurate determination of both contact points and contact angles. Colloids and Surfaces A: Physic. and Eng. Aspects. 2006;286(1-3):92-103.

[26] Yuzova VA, Semenova OV, Harshalin PA. Matierialy i componienty eliektronnykh sriedstv. SPb.: PROSPEKT; 2015, pp.11-29.

[27] Lipatov YuS. Fiziko-khimicheskiye osnovy napolnieniya polimerov. M.: KHIMIYA; 1991, pp.11-230.

[28] Lipatov Yu. Adhesion at the polymer blend-solid interfase. Composite Interfaces. 2000;8(2):151-165.

[29] Ugriumov SA. Soviershenstvovaniye tiekhnologii proizvodstva kompozitsionnykh matierialov na osnovie drieviesnykh napolnitielei i kostry lna. Dissiertatsiya na soiskaniye uchionoi stiepieni doktora tiekhnichieskikh nauk. Kostroma; 2009, pp.129-173. 